\title{
Multidimensional Perfectionism among Medical, Dental and Optometry students at SEGi University, Malaysia
}

\author{
Rebecca S.Y. Wong \\ Associate Professor \& Head of Medical Education, \\ Faculty of Medicine, SEGi University, Malaysia \\ rebecca@segi.edu.my \\ (Corresponding author) \\ Mun-Kit Loh \\ Student, Faculty of Medicine, SEGi University, \\ Malaysia \\ edwinlmk9312@gmail.com
}

Renuthuyilarasi Thavachelvan Student, Faculty of Medicine, SEGi University, Malaysia renuthuyilarasi@gmail.com

\section{Shaima Ahmed Ali}

Student, Faculty of Medicine, SEGi University, Malaysia shamosya@gmail.com

\author{
Nazrila Shaherah F. Suhaimi \\ Lecturer, Faculty of Medicine, SEGi University, \\ Malaysia \\ shaherahsuhaimi@segi.edu.my \\ Muhammed Azhar Ahamed \\ Student, Faculty of Medicine, SEGi University, \\ Malaysia \\ azhar250598@gmail.com
}

\author{
Zainah Sakhnini \\ Student, Faculty of Medicine, SEGi University, \\ Malaysia \\ zmas153@gmail.com
}

\begin{abstract}
Perfectionism is a double-edged sword: it may act as a motivational force in its adaptive state or it may bring many harmful effects in its maladaptive state. Currently, perfectionism is viewed as a multidimensional construct with three orientations: self-oriented perfectionism (SOP), other-oriented perfectionism (OOP) and socially-prescribed perfectionism (SPP). This cross-sectional study explored the multidimensional perfectionism of medical, dental and optometry at SEGi University, Malaysia using the Multidimensional Perfectionism Scale (MPS). Medical students scored significantly higher than both dental and optometry students in the SOP subscale $(p<0.05)$. International students had a significantly higher mean SOP subscale score than the local students, whereas those from the higher income group had a significantly higher mean SOP subscale score than those from the lower income group $(p<0.05)$. The high achievers, on the other hand, had a higher mean SOP subscale score than the non-high achievers $(p<0.05)$. Further exploration on the psychological impact of perfectionism on the students is recommended in future studies.
\end{abstract}

Keywords: self-efficacy; interdisciplinary differences, medical students, dental students, optometry students

Received 9 January 2018/Accepted 23 March 2018 @ JEHCP All rights reserved 


\section{Introduction}

Perfectionism may be viewed as a personal trait characterised by a person's strive in achieving flawlessness. According to Burn (1980), perfectionists set standards that are "high beyond reach or reason" and they "strain compulsively and unremittingly toward impossible goals". Burn (1980) first conceptualised perfectionism as a unidimensional construct. However, according to Hewitt and Flett (1991), perfectionism is a multidimensional construct consisting of both personal and social components. The Multidimensional Perfectionism Scale (MPS) by Hewitt and Flett (199I) determined three dimensions of perfectionism which are self-oriented perfectionism (SOP), other-oriented perfectionism (OOP) and socially-prescribed perfectionism (SPP).

A self-oriented perfectionist is characterised by self-implementation of extremely high goals, embracement of the 'all or none principle' and criticism of one's performance and behaviour. On the other hand, another-oriented perfectionist usually shows critical assessment of other's performance, a lack of trust in others, possess hostile feelings towards others and also constantly find fault with them, whereas socially-prescribed perfectionists usually hold the belief that a person can only be satisfied if their standards are being achieved, and they believe people set very high standards for themselves (Hewitt \& Flett, 2004).

Several instruments or scales are commonly used to measure perfectionism in past research. Some examples of these instruments include the Robert Hill's perfectionism scale (Hill et al., 2004), Burn Scale (Burn, 1980), Frost Multidimensional Perfectionism Scale (FMPS) (Frost, Marten, Lahart \& Rosenblaste, 1990), Perfectionism Questionnaire (Rheaume et al., 2000), Adaptive/Maladaptive Perfectionism Scale (Rice \& Preusser, 2002), as well as the Hewitt-Flett's Multidimensional Perfectionism Scale (MPS) (Hewitt \& Flett, 199I). A detailed review on these instruments has been carried out by Stairs et al., 2012. In this study, the MPS was used to measure perfectionism of the subjects.

\section{Adaptive and maladaptive perfectionism}

In general, there are two aspects of perfectionism, i.e. the positive and negative aspects. In the positive or adaptive form, perfectionism can be a motivation energy giving rise to great 
performance (Roedell, 1984). The positive form also includes a preference in handling issues or surrounding matters in an orderly and organized manner, striving to be the best, and being particular with tasks and performance (Rice, Leever, Noggle \& Lapsley, 2007). On the other hand, the negative form, also known as the maladaptive form, is accompanied by high criticism and negativity, anxiety and inconsistent thoughts when one is unable to achieve his or her expected standards. This form of perfectionism is self-handicapping, and may lead to procrastination, in which one avoids doing tasks which have been assigned (Hugh, Angus, Maria \& Kelly, 2008).

Impact of maladaptive perfectionism

There are pros and cons of being a perfectionist. In its maladaptive form, perfectionism drives a person to set and achieve unrealistic goals, leading to detrimental effects and a chronic sense of failure. In the published literature, perfectionism has been related to psychological problems such as social phobia (Hesler, 20I5), anxiety (Klibert, Langhinrichsen-Rohling \& Saito, 2005), depression (Huggins, Davis, Rooney \& Kane, 2008) and eating disorders (Woodside et al, 2002), whereas astatistical significant association between perfectionism and social anxiety $(p<0.001)$ was reported in a Malaysian study among university students (Al-Naggar, Bobryshev \& Alabsi, 20I3).

In an Iranian study, it was shown that negative perfectionism acted as a predictor of depression and anxiety which had a negative impact on academic achievement (Roohafzaet. al., 2010). In addition, a person having unrealistic expectations of himself and being selfcritical is at a higher risk of suicide ideation. For instance, in one study carried out on 405 university students, suicidal ideation was associated with those who scored higher in perfectionism (Hamilton \& Schweitzer, 2000).

Past research has also related perfectionism to marital satisfaction among graduate students. It was reported that there was no significant correlation between self-perfectionism and marital satisfaction $(p>0.05)$. However, dyadic perfectionism was negatively and significantly correlated to marital satisfaction $(p<0.01)$, suggesting that those who hold high standards for their partners tend to be less satisfied with their marriage (Foo et al., 2015). 


\section{Impact of adaptive perfectionism}

In the adaptive form, perfectionism serves as a motivational force for one to achieve his goals. Stoeber, Feast and Hayward (2009) demonstrated that perfectionistic striving students were more industrious workers when pursuing academic success. One study has reported that self-oriented perfectionism was significantly related to students' motivation and learning strategies in a positive and adaptive manner, (Mills \& Blankstein, 2000), whereas another study demonstrated that those who were adaptive perfectionists scored significantly higher in general self-efficacy and social self-efficacy when compared to the maladaptive perfectionists and non-perfectionists among college students (Locicero\& Ashby, 2010).

In a South Korean study carried out on 200 college students, both adaptive perfectionists and non-perfectionists were reported to have higher levels of psychological wellbeing, life satisfaction and self-esteem when compared to maladaptive perfectionists, although the differences were statistically not significant (Park \& Jeong, 20I5). Other studies, on the other hand, have demonstrated a significant relationship between adaptive perfectionism and several positive outcome variables such as active coping (Dunkley et al., 2000), conscientiousness and higher academic achievements (Enns, Cox, Sareen \& Freeman, 200I).

\section{Demographic factors and perfectionism}

Several studies have investigated the effects of demographic factors on perfectionism. In the published literature, researchers have differing opinions on gender differences in perfectionism. While some have shown that gender does not play a role in perfectionism (Stoeber \& Stoeber, 2009), others have demonstrated gender differences in perfectionism (Ghosh \& Roy, 2017; Landa \& Bybee, 2007). Other demographic factors that have been shown to have an influence on perfectionism include socioeconomic status (Krstic \& Kevereski, 20I5; Lyman \& Luthar, 2014), and ethnicity (Chang, 1998).

\section{The present study}

Although many studies have investigated perfectionism among students at different levels of education, multidisciplinary studies that compare perfectionism among medical and health 
sciences students are lacking in the published literature. The present study, therefore, aimed to explore multidimensional perfectionism among the medical, dental and optometry students at SEGi University, Malaysia. It also investigated the effects of various demographic factors on multidimensional perfectionism of these students and whether the latter had an effect on their academic performance.

\section{Method}

Study design and sample size

This cross-sectional study was conducted on 86 medical, 81 dental and 64 optometry students, who were Year I and Year 2 students of the Bachelor of Medicine and Surgery (MBBS), Bachelor of Dental Science (BDS) and Bachelor of Optometry (BO) programs of SEGi University, Malaysia respectively.

\section{Study instrument}

The Multidimensional Perfectionism Scale (MPS) (Hewitt \& Flett, 1991)was used to assess multidimensional perfectionism of the participants. The MPS has three subscales, namely the self-oriented perfectionism (SOP), other-oriented perfectionism (OOP) and sociallyprescribed perfectionism (SPP) subscales. Each sub-scale comprises of 15 items. Eighteen out of the 45 items in the MPS are reversely scored. Responses of all 45 items were assessed using a Likert scale ranging from I to 7, with I indicating "strongly disagree" and 7 indicating "strongly agree". The subscale score was obtained by adding the scores of each item within a particular subscale. A higher score indicates a higher level of perfectionism. Sample items of each subscale are given in Table I. Demographic data of the participants was collected before they attempted the questionnaire.

Validity and reliability of the instrument

In past research, acceptable reliability has been reported for the MPS with an overall Cronbach alpha of 0.84 for the instrument (Aminizadehet al, 2013). In the present study, a Cronbach alpha a Cronbach's alpha of 0.71 was obtained. The construct validity can be determined by factor analysis, using the Bartlett's test of sphericity $(p<0.00 \mathrm{I})$ and Kaiser- 
Mayer-Olkin (KMO) measurement of sampling adequacy (with a cutoff point of $>0.6$ ) (Loo, Ang\&Yim, 20I3). In the present study, factor analysis showed a KMO value of 0.65 (indicating sample adequacy)and the Bartlett's test of sphericity showed a $p$ value of 0.000 (indicating homogeneity of variances).

Table I

Sample items of the multidimensional perfectionism scale

\begin{tabular}{|c|c|}
\hline \multirow{2}{*}{$\begin{array}{l}\text { Subscale } \\
\text { Self-oriented perfectionism (SOP) }\end{array}$} & Sample items \\
\hline & $\begin{array}{l}\text { - When I am working on something, I cannot } \\
\text { relax until it is perfect } \\
\text { - One of my goals is to be perfect in everything I } \\
\text { do }\end{array}$ \\
\hline $\begin{array}{l}\text { Other-oriented } \\
\text { (OOP) }\end{array}$ & $\begin{array}{l}\text { - I am not likely to criticize someone for giving up } \\
\text { too easily } \\
\text { - It is not important that people I am close to are } \\
\text { successful }\end{array}$ \\
\hline $\begin{array}{l}\text { Socially-prescribed } \\
\text { (SPP) }\end{array}$ & $\begin{array}{l}\text { - I find it difficult to meet others' expectations of } \\
\text { me } \\
\text { - Those around me readily accept that I can make } \\
\text { mistakes too }\end{array}$ \\
\hline
\end{tabular}

Ethics approval, permission and consent

This study was carried out after obtaining approval from the Research and Ethics Committee of SEGi University (approval no.: SEGi/RIMC/FOM/I/20I7). Written permission from the deans of the Faculty of Medicine, Faculty of Dentistry and the Faculty of Optometry and Vision Sciences were obtained before commencement of the study. Participation in the study was voluntary and a written consent was obtained from each participant. The data obtained is treated with strict confidentiality.

\section{Statistical analysis}

Data analysis was carried out using the Statistical Package for the Social Sciences (SPSS) software version 22. Comparisons of means was carried out using Analysis of Variance (ANOVA) and t-test. Pearson's correlation was used to determine the relationship between two continuous variables. A $p$ value of $\leq 0.05$ was considered statistically significant 


\section{Result}

Demographic data

A total of $23 \mathrm{I}$ students (comprising of 86 medical, $8 \mathrm{I}$ dental and 64 optometry) took part in this cross-sectional study. The students aged between 17 and 25 years $(M=20.73, S D=1.30)$. There were 77 (33.3\%) male and I54 (66.7\%) female students. Local students made up $81.8 \%(n=189)$ of the sample, while $18.2 \%$ of the students $(n=42)$ were international students. According to household income, 169 students (73.2\%) belong to the lower income group [household income < Ringgit Malaysia (RM) 5000], 55 (23.8\%), higher income group (>RM 5000) while 7 (3.0\%) students did not specify their household income.

Interdisciplinary differences in mean multidimensional perfectionism scale (MPS) score among medical, dental and optometry students

The mean subscale scores of the multidimensional perfectionism scale (MPS) for medical, dental and optometry students are summarised in Table 2. Overall, the mean scores for the self-oriented perfectionism (SOP), other-oriented perfectionism (OOP) and sociallyprescribed perfectionism (SPP) subscales were $70.13(S D=13.54), 57.11 \quad(S D=10.00)$ and $60.84(S D=8.98)$ respectively. Analysis of Variance (ANOVA) was statistically significant $[F(2,228)=10.87 ; p=0.000)$ when comparing the mean scores of medical, dental and optometry students for the self-oriented perfectionism (SOP) subscale. However, ANOVA was not significant for the mean OOP $(F(2,228)=1.70 ; p=0.184)$ and $\operatorname{SSP}(F(2,28)=0.10)$; $p=0.902)$ subscale scores. The medical students scored significantly higher than the dental $(p=0.000)$ and optometry students $(p=0.000)$, whereas the dental students scored significantly higher than the optometry students $(p=0.000)($ Table 3$)$.

Table 2

Mean multidimensional perfectionism scale (MPS) scores of medical, dental and optometry students

\begin{tabular}{llccc}
\hline Subscale & Discipline & $\mathrm{N}$ & Mean & SD \\
\hline \multirow{3}{*}{ Self-oriented perfectionism (SOP) } & Medicine & 86 & 75.02 & 13.65 \\
& Dentistry & 81 & 68.70 & 13.05 \\
& Optometry & 64 & 65.38 & 11.97 \\
& Overall & 231 & 70.13 & 13.54 \\
Other-oriented perfectionism (OOP) & Medicine & 86 & 57.08 & 12.68 \\
& Dentistry & 81 & 58.48 & 8.25 \\
& Optometry & 64 & 55.41 & 7.48 \\
Socially-prescribed perfectionism (SPP) & Overall & 231 & 57.11 & 10.00 \\
& Medicine & 86 & 61.14 & 9.78 \\
& Dentistry & 81 & 60.51 & 8.39 \\
\hline
\end{tabular}


Table 3

Interdisciplinary differences in mean self-oriented perfectionism subscale scores

\begin{tabular}{lllllll}
\hline Discipline & Mean & SD & Discipline & Mean & SD & P value \\
\hline Medical & 75.02 & 13.65 & Dental & 68.70 & 13.05 & 0.006 \\
Medical & 75.02 & 13.65 & Optometry & 65.38 & 11.97 & 0.000 \\
Dental & 68.70 & 13.05 & Optometry & 65.38 & 11.97 & 0.000
\end{tabular}

*Only significant comparisons are shown.

Effects of demographic factors on multidimensional perfectionism

Age $(M=2-.73, S D=I .30)$ was not significantly correlated to the SOP $[r(23 \mathrm{I})=0.1 \mathrm{I}, p=0.10 \mathrm{I}]$, OOP $[r(231)=-0.087, p=0.186]$ or SPP $[r(231)=-0.009, p=0.892]$ subscales (results not shown). There were also no statistical significant gender differences for all three subscales $(p>0.05$, results not shown). On the other hand, the students' nationality and income group were shown to have an effect on multidimensional perfectionism. International students $(M=74.67, S D=13.24)$ reported a significantly higher mean SOP subscale scores than local students $(M=69.13, S D=13.24 ; p=0.016)$ and the differences in the mean OOP and SPP subscale scores were statistically not significant $(p>0.05)$ (Table 4$)$.

The students were divided into two income groups i.e. lower income group (monthly household income $\leq$ RM 5000) and higher income group (monthly household income $>$ RM 5000). Those from the higher income group had a significant higher mean SOP subscale score $(M=74.38, S D=|3.8|)$ than those from the lower income group $(M=68.99, S D=\mid 3.32$; $p=0.010$ ) whereas differences for the mean OOP and SPP subscale scores between the two income groups were statistically not significant $(p>0.005)$ (Table 5).

Table 4

Effects of nationality on multidimensional perfectionism

SOP OOP SPP

$\begin{array}{lccccccccc}\text { Nationality } & \text { Mean } & \text { SD } & P \text { value } & \text { Mean } & \text { SD } & P \text { value } & \text { Mean } & \text { SD } & P \text { value } \\ \text { Local } & 69.13 & 13.24 & 0.016 & 56.87 & 9.90 & 0.449 & 60.92 & 9.12 & 0.787 \\ \text { International } & 74.67 & 14.09 & & 58.17 & 10.48 & & 60.50 & 8.36 & \end{array}$

*SOP=self-oriented perfectionism, OOP=other-oriented perfectionism, SPP=Socially-prescribed perfectionism 
Table 5

Effects of household income on multidimensional perfectionism

\begin{tabular}{lccccccccc}
\hline & \multicolumn{3}{c}{ SOP } & \multicolumn{3}{c}{ OOP } & & & SPP \\
\hline $\begin{array}{l}\text { Household } \\
\text { income }\end{array}$ & Mean & SD & P value & Mean & SD & P value & Mean & SD & P value \\
$\begin{array}{l}\text { Low } \\
\text { income }\end{array}$ & 68.99 & 13.32 & 0.010 & 56.60 & 9.82 & 0.140 & 60.54 & 8.91 & 0.338 \\
$\begin{array}{l}\text { High } \\
\text { income }\end{array}$ & 74.38 & 13.81 & & 58.91 & 10.60 & & 61.89 & 9.55 & \\
\hline
\end{tabular}

*SOP=self-oriented perfectionism, OOP=other-oriented perfectionism, SPP=Socially-prescribed perfectionism.

\section{Effects of multidimensional perfectionism on academic achievements}

The students were divided into two groups according to their academic performance i.e. high achievers and non-high achievers. High achievers refer to those who achieved the highest grades compared to their peers. Out of the 23I students, II4 (44.6\%) were nonhigh achievers, 103 (44.6\%) were high achievers and I4 (6.1\%) did not specify their results. There were no statistical significant differences in the mean subscale scores for OOP and SPP between the high achievers and non-high achievers $(p>0.005)$. However, the high achievers $(M=72.72, S D=13.27)$ were observed to have a significantly higher mean SOP subscale score than the non-high achievers $(M=67.87, S D=13.40 ; p=0.008)($ Table 6).

Table 6

Effects of self-efficacy on academic achievements

\begin{tabular}{|c|c|c|c|c|c|c|c|c|c|}
\hline & SOP & & & OOP & & & SPP & & \\
\hline $\begin{array}{l}\text { Academic } \\
\text { achievement }\end{array}$ & Mean & SD & $\begin{array}{l}P \\
\text { value }\end{array}$ & Mean & SD & $\begin{array}{l}P \\
\text { value }\end{array}$ & Mean & SD & $\begin{array}{l}P \\
\text { value }\end{array}$ \\
\hline High achievers & 72.72 & $\begin{array}{l}13.2 \\
7\end{array}$ & 0.008 & 58.33 & $\begin{array}{l}10.4 \\
8\end{array}$ & 0.107 & 60.55 & 9.89 & 0.768 \\
\hline $\begin{array}{l}\text { Non-high } \\
\text { achievers }\end{array}$ & 67.87 & $\begin{array}{l}13.4 \\
0\end{array}$ & & 56.11 & 9.66 & & 60.92 & 8.44 & \\
\hline
\end{tabular}

*SOP=self-oriented perfectionism, OOP=other-oriented perfectionism, SPP=Socially-prescribed perfectionism. 


\section{Discussion}

This study investigated multidimensional perfectionism among medical, dental and optometry students at SEGi University, Malaysia. Using the MPS, significant interdisciplinary differences were only observed in the SOP subscale. The medical students scored significantly higher than the dental $(p=0.000)$ and optometry students $(p=0.000)$, whereas the dental students scored significantly higher than the optometry students $(p=0.000)$. Literature on interdisciplinary differences in perfectionism is scarse, making it hard to compare results of the current study with previous ones. The demanding nature of the medical and dental curricula may help explain why both medical and dental students scored significantly higher than the optometry students in the SOP subscale. The challenges and difficulties faced in the pursuit of their studies may have contributed to the medical and dental students imposing high standards and expectations on themselves, making them selforiented perfectionists.

Exploration of the effects of demographic factors on perfectionism showed that age was not significantly correlated to any of the MPS subscale scores and that there were also no gender differences in the mean MPS subscale scores among the students. Findings in the present study are in tandem with those from a previous study that investigated perfectionism in 22 domains of life. The study reported that being perfectionist was largely independent of gender and age in general as well as in the individual domains (Stoeber \& Stoeber, 2009).

However, some previous studies show that gender has an influence on perfectionism. Findings of the present study contradict that of one previous study, which reported that self-image discrepancy and perfectionism were both markedly lower in older women $(M=33.74$ years) than younger ones $(M=19.85$ years) (Landa \& Bybee, 2007). In a more recent study, Ghosh and Roy (2017) investigated gender differences among 150 undergraduate and postgraduate students in the National Capital Region of India. It was reported that significant gender differences were observed in the OOP and SPP subscales.

Interestingly, international students $(M=74.67, S D=13.24)$ demonstrated a significantly higher mean SOP subscale scores than local students $(M=69.13, S D=13.24 ; p=0.016)$ in the present study. It is not sure why such a difference existed. Research has shown that ethnicity plays a role in perfectionism. One study revealed that Asian-American students showed higher 
levels of perfectionism as compared to Caucasian students. The former scored significantly higher than the latter in four areas of perfectionism, namely, concerns over mistake $(p<0.00 \mathrm{I})$, parental expectations $(p<0.00 \mathrm{I})$, parental criticism $(p<0.00 \mathrm{I})$ and doubts about action $(p<0.001)$ (Chang, 1998). Therefore, different cultural and ethnic backgrounds of the local students, when compared with those of the international students, may help explain the observed findings in this study.

In addition, perfectionism was also found to be influenced by the household income of the students. Those in the higher income group (>RM 5000) demonstrated a significantly higher mean SOP subscale score than those in the lower income group $(\leq R M 5000)(p<0.05)$. This finding is in tandem with that of a previous study conducted on gifted children. The study showed that families of gifted children with higher socioeconomic status imposed excessive demands on their children and had a greater impact on perfectionism than those of lower socioeconomic status (Krstic \& Kevereski, 20I5). In another study that compared perfectionism among gifted youth from extremes of socioeconomic status, affluent girls was shown to have marked elevations in perfectionistic tendencies, peer envy and body dissatisfaction when compared with those from low income families (Lyman \& Luthar, 20I4).

A statistical significant difference was only observed in the SOP subscale when comparing the high achievers and non-high achievers, with the former scoring significantly higher than the latter. Previous research has investigated the relationship between perfectionism and academic achievement (Arthur \& Hayward, 1997; Enns, Cox, Sareen\& Freeman, 200I;Kyeon, Cho, Hwang \& Lee, 20I0; Roohafzaet al., 2010).However, it is worth mentioning that the influence of perfectionism on academic performance depends on its orientation (i.e. SOP, OOP or SPP) as well as whether it is in the adaptive or maladaptive form.For example, Enns, Cox, Sareen and Freeman (200I) showed that a significant correlation was observed between adaptive perfectionism, baseline academic performance, performance expectations and conscientiousness whereas maladaptive perfectionism was shown to have a significant correlation with baseline distress symptoms and neuroticism. The former was predictive of academic performance dissatisfaction and the latter, symptoms of depression and hopelessness.

In one study, SPP has been associated with lower academic achievement among postsecondary students (Arthur \& Hayward, 1997), whereas SOP was associated significantly and positively with grade point average $(r=0.173, p<0.05)$ and engagement 
$(r=0.449, p<0.01)$ among medical students in another study (Kyeon, Cho, Hwang \& Lee, 2010). On the other hand, negative and positive perfectionisms were found to be negative and positive predictors for academic achievement, respectively in an Iranian study (Roohafzaet al., 20l0). Besides having an influence in academic achievement, it has also been demonstrated that academic procrastination was moderately and significantly correlated to SOP and OOP ( $p<0.01)$, and strongly correlated to SPP ( $p<0.01)$ (Ghosh and Roy, 20I7). While perfectionism may be a motivational force, it may also bring about negative effects on the students. In one study carried out on 159 medical students from University of Ulsan college of Medicine, it was reported that perfectionism was significantly correlated to academic stress level $(p<0.00 \mathrm{I})(\mathrm{Kim}$ et al., 20I7). In another study carried out on 244 premed and medical students, Yu, Chae, and Chang (2016) reported a significant correlation between academic burnout and socially-prescribed perfectionism $(r=0.428, p<0.0 \mathrm{I})$.

\section{Implications and limitations of the study}

Findings of this study and previous studies imply that the negative impact of perfectionism must not be overlooked despite the fact that perfectionism may be a motivation for the high achievers to reach higher goals and standards. Therefore, further research is necessary to investigate the psychological impact of perfectionism on thestudents. The present study was limited by a small sample size comprising of students of three disciplines from a single university. Further research should include a bigger sample size, with the involvement of more disciplines. It would also be beneficial if a multi-institutional study could be carried out to explore if perfectionism differ among students from different universities.

\section{Conclusion}

Several conclusions can be drawn from this study. Firstly, a significant interdisciplinary difference existed in self-oriented perfectionism among medical, dental and optometry students at SEGi University, Malaysia. Secondly, multidimensional perfectionism was independent of age and gender. However, significant differences according to nationality and income existed in self-oriented perfectionism among these students. Lastly, self-oriented perfectionism had a significant effect on the academic achievement of the students.

Findings of this study imply that further exploration on the psychological effects of perfectionism on the students is necessary. Although the high achievers had a significantly 
higher mean SOP subscale score than the non-high achiever, it is not sure whether perfectionism also had a negative impact on these high achievers as the perfectionists have been associated with a high level of academic stress (Kim et al., 2017) and are at risk of academic burnout (Yu, Chae, \& Chang, 2016).

\section{Acknowledgement}

The authors would like to thank the Prof Samiah Yasmin Abdul Kadir (Dean, Faculty of Medicine, SEGi University), Datuk Dr. Khairiyah Abd Muttalib (Dean, Faculty of Dentistry, SEGi University) and Professor Dr. Azrin Esmady Ariffin (Dean, Faculty of Optometry \& Vision Sciences, SEGi University) for granting the authors permission to conduct the study on their students.

\section{References}

Al-Naggar R.A., Bobryshev Y.V., \& Alabsi M. (20I3). Perfectionism and social anxiety among university students in Malaysia. ASEAN Journal of Psychiatry, I4(I), $5 \mathrm{I}-58$.

Aminizadeh, S., Dolatshahi, B., Pourshahbaz, A., Babapour, B., Yousefzadeh, I., Zamanshoar, E. \& Eshaghi, M. (20I3). Psychometric properties of multidimensional perfectionism scale (MPS). Practice and Clinical Psychology, I (4), 205-2I 0.

Arthur, N., \& Hayward, L. (1997). The relationships between perfectionism, standards for academic achievement, and emotional distress in postsecondary students. Journal of College Student Development, 38, (6), 622-633.

Burns, D.D. (1980).The perfectionist's script for self-defeat. Psychology Today, 14, 34-52.

Chang, E.C. (1998). Cultural differences, perfectionism, and suicidal risk in a college population: does social problem solving still matter? Cognitive Therapy and Research, 22(3), 237-254.

Dunkley, D. M., Blankstein, K. R., Halsall, J., Williams, M., \&Winkworth, G. (2000).The relation between perfectionism and distress: Hassles, coping, and perceived socialsupport as mediators and moderators. Journal of Counselling Psychology, 47(4), 437-453. 
Enns, M. W., Cox, B. J., Sareen, J., \& Freeman, P. (200I). Adaptive and maladaptive perfectionism in medical students: A longitudinal investigation. Medical Education, 35, 1034-1042.

Foo, F. M., Hassan, S. A., Baba, M., Talib, M. A., \& Zakaria, N. S. (20I5). Relationship between perfectionism and marital satisfaction among graduate students. International Journal of Education and Research, 3, 179 - 186.

Frost, R.O., Marten, P., Lahart C., \& Rosenblate, R. (1990). The dimensions of perfectionism. Cognitive Therapy and Research, 14, 449-468.

Ghosh, R. \& Roy, S. (2017). Relating multidimensional perfectionism and academic procrastination among Indian university students: Is there any gender divide? Gender in Management: An International Journal, 32(8), 518-534.

Hamilton, T.K., \& Schweitzer, R.D. (2000). The cost of being perfect: perfectionism and suicide ideation in university students. Australia \& New Zealand Journal of Psychiatry, 34(5), 829-835.

Hesler, K. (20I5). Perfectionism, social support, and social anxiety in college students. The Proceedings of Great Day, 4, 2 I-34.

Hewitt, P. L., \& Flett, G. L. (199I). Perfectionism in the self and social contexts: Conceptualization, assessment, and association with psychopathology. Journal of Personality and Social Psychology, 60(3), 456-470.

Hill, R. W., Huelsmann, T. J., Furr, R. M., Kibler, J., Vicente, B. B., \& Kennedy, C. (2004). A new measure of perfectionism Inventory. Journal of Personality Assessment, 82, 80-9I.

Huggins L, Davis MC, Rooney R, \& Kane R. (2008). Socially prescribed and self-oriented perfectionism as predictors of depressive diagnosis in preadolescents. Australian Journal of Guidance and Counselling, 18(02), 182-94.

Hugh, K., Angus, F., Maria, G., \& Kelly, M. (2008). When a high distinction isn't good enough: a review of perfectionism and self-handicapping. Australian Educational Researcher, 3, $21-36$.

Kim, C., Seockhoon, C., Suyeon, L., Soyoun, Y., \& Boram, P. (20I7). Perfectionism is related with academic stress in medical student. European Psychiatry, 4I, S690.

Klibert I.I., Langhinrichsen-Rohling I., \& Saito M. (2005). Adaptive and maladaptive aspects of self-oriented versus socially prescribed perfectionism. Journal of College Student Development, 46, I4I-156.

Krstic, M., \& Kevereski, L. (20I5). The impact of socioeconomic status on the occurrence of perfectionism in primary school gifted students. Research in Pedagogy, 5(I), 42-5I. 
Kyeon, Y.G., Cho, S.M., Hwang, H.G., \& Lee, K.U.(20I0).The effects of perfectionism on academic achievement in medical students. Korean Journal of Medical Education, 22(3), 205-14.

Landa, C. E., \& Bybee, J. A. (2007). Adaptive elements of aging: Self-image discrepancy, perfectionism, and eating problems. Developmental Psychology, 43, 83-93.

Locicero, K.A., \& Ashby J.S. (2000). Multidimensional perfectionism and self-reported selfefficacy in college students. Journal of College Student Psychotherapy, 15(2), 47-56.

Loo, J.L., Ang, Y.K., \& Yim, H.S. (20I3). Development and validation of a cancer awareness questionnaire for Malaysian undergraduate students of Chinese ethnicity. Asian Pacific Journal of Cancer Prevention, 14, 560-570.

Lyman, E. L., \& Luthar, S. S. (20|4). Further evidence on the "costs of privilege": perfectionism in high-achieving youth at socioeconomic extremes. Psychology in the Schools, 5 I(9), 913-930.

Mills, J.S., \& Blankstein, K.R. (2000). Perfectionism, intrinsic vs extrinsic motivation, and motivated strategies for learning: a multidimensional analysis of university students. Personality and Individual Differences, 29(6), II9I-I 204.

Park, H.J. \& Jeong, D.Y. (20I5).Psychological well-being, life satisfaction, and self-esteem among adaptive perfectionists, maladaptive perfectionists, and non-perfectionists. Personality and Individual Differences, 75, 165-170.

Rice, K. G., Leever, B. A., Noggle, C. A., \& Lapsley, D. K. (2007). Perfectionism and depressive symptoms in early adolescence. Psychology in the Schools, 5, 139 - 156.

Rice K.G., \& Preusser K.J. (2002).The adaptive/maladaptive perfectionism scale. Measurement and Evaluation in Counselling and Development, 34, 210-222.

Roedell, W. (1984). Vulnerabilities of highly gifted children. Roeper Review, 4, I27 - I30.

Roohafza, H., Afshar, H. ,Sadeghi, M. Soleymani, B., Saadaty, A., Matinpour, M., Asadollahi, G. (2010). The relationship between perfectionism and academic achievement, depression and anxiety. Iranian Journal of Psychiatry and Behavioural Sciences, 4(2): 3136.

Stairs, A. M., Smith, G. T., Zapolski, T. C. B., Combs, J. L., \& Settles, R. E. (20I2). Clarifying the construct of perfectionism. Assessment, 19(2), 146-166. 
Stoeber, J., Feast, A. R., \& Hayward, J. A. (2009). Self-oriented and socially prescribed perfectionism: Differential relationships with intrinsic and extrinsic motivation and test anxiety. Personality and Individual Differences, 23, $423-428$.

Stoeber, J, \& Stoeber, F.S. (2009). Domains of perfectionism: Prevalence and relationships with perfectionism, gender, age, and satisfaction with life. Personality and Individual Differences, 46, 530-535.

Woodside, D.B., Bulik, C.M., Halmi, K.A., Fichter, M.M., Kaplan, A., Berrettini, W.H., Strober, M., Treasure, J., Lilenfeld, L., Klump, K., \& Kaye, W.H. (2002). Personality, perfectionism, and attitudes toward eating in parents of individuals with eating disorders. International Journal of Eating Disorders, 3 I (3), 290-299.

Yu, J. H., Chae, S. J., \& Chang, K. H. (20/6). The relationship among self-efficacy, perfectionism and academic burnout in medical school students. Korean Journal of Medical Education, 28(I), 49-55. 